\title{
Dogs with Experimental Cirrhosis of the Liver but without Intrahepatic Hypertension Do Not Retain Sodium or Form Ascites
}

\author{
Bernard Unikowsky, Marvin J. Wexler, and Mortimer Levy, Departments of \\ Physiology, Medicine, and Surgery, McGill University, and the Nephrology \\ Division, Department of Medicine, and the Department of Surgery, Royal \\ Victoria Hospital, Montreal, Quebec, Canada H3G 1 Y6
}

\begin{abstract}
A B S T R A C T Dogs with portal cirrhosis but without portal hypertension (end-to-side portacaval anastomosis) retain sodium and expand plasma volume before ascites formation. In our study, dogs were subjected to bile duct ligation and simultaneous side-toside portacaval anastomosis (PCA) in order to create a canine model of hepatic cirrhosis without intrahepatic or portal hypertension. The effect of normalizing intrahepatic pressures in the face of venous outflow block on sodium handling was studied. 13 dogs survived the surgical procedures and were followed. Two dogs developed sodium retention and ascites at 5-6 wk (livers were cirrhotic) when the PCA spontaneously closed. 11 dogs were free of sodium retention and ascites for as long as $12 \mathrm{wks}$ after surgery, while ingesting $35 \mathrm{meq} / \mathrm{d}$ of sodium. In this group glomerular filtration rate remained normal throughout the period of observation and there was no expansion of plasma volume. Nine of these dogs were then fed $85 \mathrm{meq} / \mathrm{d}$ of sodium; eight remained in sodium balance and one retained sodium and went on to develop ascites. When 10-15 mg i.m. of desoxycorticosterone acetate (DOCA) was given daily, five dogs developed sodium retention and ascites, while four escaped from DOCA. Dogs who developed ascites had either a partially occluded PCA $(4 / 5)$ or a patent PCA, but with a significant portacaval pressure gradient of $9.5 \mathrm{~cm} \mathrm{H}_{2} \mathrm{O}(1 / 5)$. In all four dogs who escaped from DOCA, the PCA was widely patent and the mean pressure gradient was only $1.6 \mathrm{~cm} \mathrm{H}_{2} \mathrm{O}$. Both groups were equally cirrhotic, as judged by histological and biochemical parameters. We conclude
\end{abstract}

Dr. Unikowsky was a Research Fellow of the Medical Research Council of Canada during this study.

Received for publication 3 November 1982 and in revised form 18 June 1983. that normalizing intrahepatic pressure by providing an outflow tract for the cirrhotic liver will abolish that component of early renal tubular sodium retention not due to portal venous hypertension or ascites sequestration.

\section{INTRODUCTION}

Studies conducted in both the rat (1-3) and dog (4) with experimental portal cirrhosis of the liver, have documented that renal tubular retention of sodium occurs very early in the course of the disease and precedes the formation of ascites. In experiments designed to exclude portal venous hypertension or ascites sequestration from being determinants of urinary sodium retention, extensive studies in our laboratory (48) demonstrated that this first phase, or early sodium retention in canine cirrhosis, is unrelated to arterial hypovolemia, altered systemic hemodynamics, or hyperaldosteronism. As the liver disease progresses, new factors lead to persistent sodium retention. These include the formation of ascites, reduced dietary intake of salt in the face of third space sequestration, and gastrointestinal bleeding. Hyperaldosteronism appears and second phase or late urinary sodium retention is largely due to a compromised effective arterial blood volume (EABV). ${ }^{1}$

The observation that sodium retention precedes ascites formation in the cirrhotic dog without portal ve-

\footnotetext{
${ }^{1}$ Abbreviations used in this paper: BUN, blood urea nitrogen; $C_{\mathrm{IN}}$, inulin clearance rate; DOCA, desoxycorticosterone acetate; EABV, effective arterial blood volume; HVWP, hepatic venous wedged pressure; PCA, portacaval anastomosis; SGOT, serum glutamic oxalacetic transferase; ss-PCA, side-to-side PCA.
} 
nous hypertension (due to an end-to-side portacaval anastomosis) implies that the signal for first phase sodium retention can have only two possible causes: $(a)$ intrahepatic hypertension or some derivative thereof; or $(b)$ a humoral, metabolic, hemodynamic, or neural signal related to compromised synthetic or degradative functions of the diseased hepatic parenchyma (7). (The possibility also exists that both $(a)$ and $(b)$ may combine to provide a sodium-retaining signal to the renal tubule.)

In this study, we attempted to distinguish between these two possibilities by studying cirrhotic dogs who have a side-to-side portacaval anastomosis (ss-PCA). Such an anastomosis serves as an outflow tract from the liver, thus normalizing pressures within the liver as well as within the portal venous circulation $(9,10)$. Both hepatic arterial and portal venous blood will shunt into the abdominal inferior vena cava, thus maintaining a normal or near-normal sinusoidal pressure. Since intrahepatic pressure remains normal, there is no stimulus to excessive hepatic lymph production and ascites will not form. Thus, we have a model where hydrostatic forces are normalized from hepatic sinusoid to mesenteric capillary, and arterial hypovolemia cannot occur because of fluid sequestration within the peritoneal space or blood sequestration within the mesenteric venous circulation. ${ }^{2}$ Nevertheless, liver function remains badly compromised. Under these circumstances, the ability of the kidney in such cirrhotic animals to handle dietary sodium normally would imply that first phase sodium retention is due to intrahepatic hypertension. The appearance of urinary sodium retention in the absence of intrahepatic hypertension implies that it is due to some consequence of compromised liver function, rather than to raised intrahepatic pressures.

\section{METHODS}

Studies were performed on conditioned female dogs that had been treated and observed by the staff of the McGill Animal Centre for 2-3 mo before use. The animals weighed between 15 and $24 \mathrm{~kg}$, were kept in spacious air-conditioned pens, and were fed a standard diet of chow that contained $\sim 35$ $\mathrm{meq} / \mathrm{d}$ of sodium. Water was allowed ad lib.

Before use, the following control observations were made: weight, plasma volume, inulin clearance $\left(C_{\mathrm{IN}}\right)$, measurement of serum $\mathrm{Na}^{+}$, creatinine, blood urea nitrogen (BUN), hematocrit, and plasma protein level. Liver function was assessed by measuring plasma levels of bilirubin, alkaline phosphatase, and glutamic oxalacetic transaminase (SGOT). So-

\footnotetext{
${ }^{2}$ Arterial hypovolemia could still occur because of a primary decrease in peripheral vascular resistance. If such an event were to appear in this model, it would probably be related not to intrahepatic hypertension, but rather to the underlying hepatic disease.
}

dium balance studies were performed in appropriate metabolic cages. Details of the methods used in making these observations have been previously reported for this laboratory (4). All dogs were studied while alert and conscious and standing quietly in a Pavlov sling. When necessary they were sedated with an injection of Xylazine, $2.2 \mathrm{mg} / \mathrm{kg}$ i.m., preceded by a $1.0 \mathrm{mg}$ i.m. atropine injection.

To produce experimental cirrhosis, dogs were subjected to sterile surgery under methoxyflurane anesthesia. Through a midline abdominal incision, the common bile duct was identified and doubly ligated above the entrance of the pancreatic duct and as high as possible, to prevent fistulous reattachment of the proximal stump to the duodenum at a later date. Cholecystectomy was also performed. Care was taken to identify and ligate all accessory branches to the common bile duct. The bile duct was finally divided between the ligatures. Simultaneously, an ss-PCA of $\sim 15-18 \mathrm{~mm}$ diam was created by standard surgical techniques. The portacaval anastomosis (PCA) was made as large as possible to ensure the accommodation of both anterograde and retrograde portal flow. Most dogs tolerated this procedure very well and survived the immediate postsurgical period. At 6 and at 10-12 wk after surgery, the control observations were repeated. The dogs were then given additional salt by mouth to increase the daily sodium intake to $\sim 85 \mathrm{meq} / \mathrm{d}$. After the dogs were allowed to come into balance on the new diet, 24 -h urine collections were made. $10-15 \mathrm{mg}$ desoxycorticosterone acetate (DOCA) was then administered by intramuscular injection on a daily basis. When it was clear whether or not DOCA escape was occurring, as judged by daily body weights and 24-h urinary sodium balances, the injections were stopped and the animals subjected to final experimentation. Under pentothal (Nembutal) anesthesia $(25 \mathrm{mg} / \mathrm{kg}$ i.v.) the following procedures were done. The thoracic duct in the left neck was dissected out and carefully assessed for fullness and distension (7). The abdomen was opened and the peritoneal space carefully examined for the presence of ascites. Cannulas were inserted into the inferior vena cava and the portal vein both above and below the anastomosis for the recording of pressures by saline manometry. Zero base line was taken at the level of the anterior surface of the vertebral column. In some experiments, pressure was recorded after the anastomosis was clamped closed. Several dogs were transported to the Department of Radiology, Royal Victoria Hospital, for the measurement of hepatic venous wedge pressure (HVWP) under fluoroscopic control. After the pressure measurements, biopsies of the liver and kidney were taken and the animal killed. The area of the anastomosis was then excised to examine patency of the shunt.

Analytical techniques for the measurement of inulin, electrolytes, and liver function tests were all previously discussed in detail for this laboratory (4).

The data were evaluated for statistical significance at the $5 \%$ probability level with either the paired or unpaired $t$ test. All data are expressed as the mean \pm SEM (11).

\section{RESULTS}

13 dogs survived the surgical procedures, developed chronic biliary cirrhosis, and served as the subject matter for this report. All dogs remained in good health, displaying normal appetites and activity for $\sim 4-6 \mathrm{wk}$ after the surgical procedures. After $6 \mathrm{wk}$, the animals developed progressive lethargy as the cir- 
TABLE I

Some Clinical Features of 13 Dogs before Surgery and after Ligation of the Common Bile Duct and Creation of an ss-PCA

\begin{tabular}{|c|c|c|c|}
\hline & \multirow[b]{2}{*}{ Control } & \multicolumn{2}{|c|}{ Postoperative } \\
\hline & & $6 \mathrm{wk}$ & $\begin{array}{l}\text { Postmortem } \\
\text { (cirrhosis) }^{\circ}\end{array}$ \\
\hline Body weight $(k g)$ & $18.2 \pm 0.97$ & $13.4 \pm 0.97 \ddagger$ & $12.7 \pm 1.3 \ddagger$ \\
\hline Hematocrit (\%) & $48 \pm 1.6$ & $43 \pm 1.8 !$ & $37 \pm 2.81 \S$ \\
\hline Serum protein, $(\mathrm{g} / 100 \mathrm{ml})$ & $6.5 \pm 0.3$ & $5.7 \pm 0.4 \rrbracket$ & $4.4 \pm 0.41 \S$ \\
\hline Plasma sodium, (meq/liter) & $149 \pm 0.9$ & $149 \pm 1.7$ & $149 \pm 3.1$ \\
\hline BUN $(m g / 100 m l)$ & $13.4 \pm 1.8$ & $7.2 \pm 1.01$ & $6.4 \pm 1.2 \downarrow$ \\
\hline Serum creatinine, $(\mathrm{mg} / 100 \mathrm{ml})$ & $0.83 \pm 0.03$ & $0.70 \pm 0.1 \ddagger$ & $0.53 \pm 0.1 \ddagger \S$ \\
\hline Bilirubin $(\mathrm{mg} / 100 \mathrm{ml})$ & $0.85 \pm 0.2$ & $10.9 \pm 4.2 \downarrow$ & $3.4 \pm 0.65 \ddagger \S$ \\
\hline SGOT $(I U)$ & $23.4 \pm 2.6$ & $75.2 \pm 15 \ddagger$ & $67.6 \pm 14 \rrbracket$ \\
\hline Alkaline phosphatase $(I U)$ & $36.8 \pm 9.5$ & $58.2 \pm 23 \ddagger$ & $400 \pm 71 \ddagger \S$ \\
\hline$C_{\mathrm{IN}}(\operatorname{ml} / \min )$ & $52 \pm 3.5$ & $57 \pm 5.2$ & $61 \pm 6.6$ \\
\hline
\end{tabular}

rhotic process advanced. All animals had severe disturbance in liver function and were deeply jaundiced.

Table I summarizes some important features of all 13 dogs for the control and experimental phases of the study. Progression of the liver disease was associated with marked weight loss, despite normal food intake. Hematocrit presumably declined because of the liver disease; gastrointestinal bleeding was not a feature of these dogs unless diarrhea appeared, which happened in several dogs late in their cirrhotic course. The decline in serum protein, and the increment in bilirubin, SGOT, and alkaline phosphatase reflected the progression of the cirrhotic process. The BUN declined because of liver damage, while the serum creatinine declined because of a diminishing muscle mass. This pattern of low SGOT and high alkaline phosphatase is a feature of dogs with biliary cirrhosis, as is the decline of bilirubin values from previous very high levels. Note that serum $\mathrm{Na}^{+}$levels remain constant throughout the period of observation, suggesting no inappropriate release of autidiuretic hormone or renal retention of water. Mean glomerular filtration rate, as measured by $C_{\mathrm{IN}}$, tended to remain constant during the course of liver disease.

Kidney biopsies taken at the time the animals were killed, when all dogs had definite cirrhosis, showed normal tissue, save for mild mesangial thickening in some glomeruli.

All liver biopsies showed changes consistent with chronic biliary cirrhosis. Four of the biopsies showed early changes, with marked cholestasis, bile duct proliferation, and marked fibrosis, but without complete portal bridging or formation of regenerative nodules. The remaining nine dogs had more complete changes, with more marked fibrosis, septal formation, and fibrous bridging of the portal areas and the appearance of regenerative nodules. The lack of complete fibrous bridging or the absence of nodules should not be taken as evidence for lack of cirrhosis, but rather as an early stage of the cirrhotic process (12). There is vascular and parenchymal destruction in these earlier stages. Dogs with bile duct ligation but without PCA will often have such histological changes in the presence of portal venous hypertension, marked liver function disturbances, ascites, and urinary sodium retention. ${ }^{3}$ In other words, the absence of complete bridging and nodular formation can still yield a physiological picture identical to that seen when the biopsy reveals changes of classical cirrhosis.

Two of the 13 dogs spontaneously developed gross ascites at 5-6 wk after bile duct ligation, while ingesting the standard chow diet of $\sim 35 \mathrm{meq} \mathrm{Na}^{+} / \mathrm{d}$. Their liver function tests, $C_{\mathrm{IN}}$, and plasma sodium and plasma protein values did not significantly differ from the group means shown in Table I. They displayed marked sodium retention with an aliquot of urine from a 24-h collection measuring 3 and $5.0 \mathrm{meq} / \mathrm{liter}$, respectively, whereas the urinary sodium values during the preoperative period had averaged 114 and 84 meq/liter, respectively. Both dogs clearly had chronic

\footnotetext{
${ }^{3}$ Levy, M., M. J. Wexler, and C. Fechner. Submitted for publication.
} 
cirrhosis of the liver when killed, one showing early changes and the other showing more advanced changes. In each case, the PCA had been obliterated and closed by a reepithelization process. Portal venous pressure measured $27.0 \mathrm{~cm} \mathrm{H}_{2} \mathrm{O}$ in each dog, while abdominal vena caval pressure was $3.5 \mathrm{~cm} \mathrm{H}_{2} \mathrm{O} .{ }^{4}$ The periportal lymphatics and thoracic duct in each dog were massively dilated and contained abundant lymph under great pressure.

Because the PCA closed in these two animals and portal venous hypertension supervened, they are no longer considered in this report; the remainder of our data deal with the 11 dogs that remained free of ascites and urinary sodium retention until the end-point of the study, i.e., the appearance of chronic biliary cirrhosis.

The 11 dogs that remained free of ascites had plasma compositional changes at 10-12 wks after surgery that did not differ significantly from the data given in Table I. Table II summarizes additional data from these 11 dogs while they were ingesting a daily sodium intake of 35 meq. All dogs were free of ascites as determined either by careful abdominal examination after sedation or by paracentesis-techniques previously shown by this laboratory to be extremely accurate in detecting ascites (4). All 11 dogs suffered significant weight loss (Table II). Plasma volume in absolute terms did not increase from the normal to the cirrhotic phase, but in terms of volume factored for body weight, there was a significant increment. This phenomenon will be commented upon in the Discussion section. The dogs remained in sodium balance in the final phase of the experiment, as indicated by the unchanged urinary sodium concentration and 24-h sodium output. This latter value averaged $37.6 \pm 5.9 \mathrm{meq} / \mathrm{d}$ for the $11 \mathrm{dogs}$ while they were ingesting 35 meq sodium daily. Normal dogs $(n=6)$ excreted an average of $30.4 \pm 3 \mathrm{meq} /$ $\mathrm{d}$ while on an identical diet.

If we compare these 11 experimental dogs with another group of 20 dogs with chronic bile duct ligation (but without any interference to normal portal or caval venous drainage) studied in this laboratory as part of a separate protocol, a different pattern emerges. In this latter experimental group, ingesting an identical diet of $35 \mathrm{meq} \mathrm{Na}{ }^{+} / \mathrm{d}$ and kept in the Animal Centre under identical conditions, daily sodium excretion before bile duct obstruction averaged $31.8 \pm 2.1 \mathrm{meq} / \mathrm{d}$. As these animals were followed serially, weekly sodium balances conducted over a 3-d period indicated that for each dog urinary sodium retention preceded ascites

\footnotetext{
4 The averge portal pressure in a large number of normal dogs in our laboratory is $12 \pm 0.30 \mathrm{~cm} \mathrm{H}_{2} \mathrm{O}$, whereas in dogs with portal cirrhosis it measured $24.1 \pm 0.44 \mathrm{~cm} \mathrm{H}_{2} \mathrm{O}$.
}

TABLE II

Data from 11 Cirrhotic Dogs in Sodium Balance and Ascites-free 10-12 Wk Postbiliary Obstruction

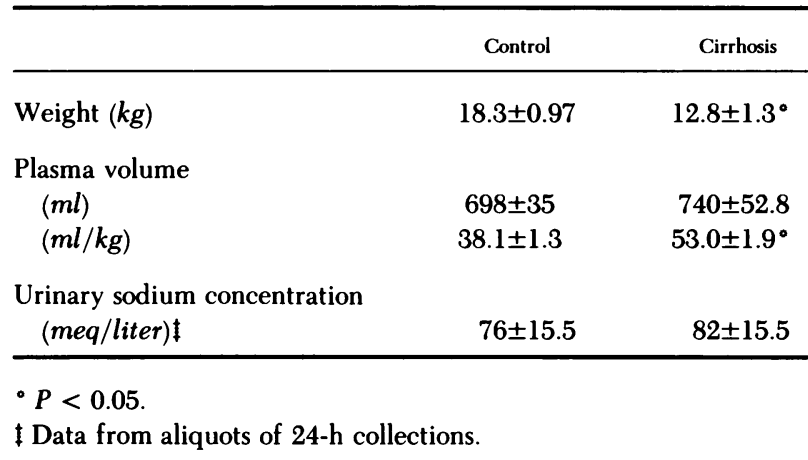

formation. In two dogs, significant sodium retention

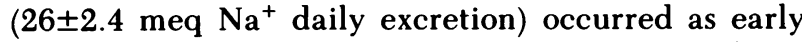
as 5 wks postbiliary obstruction; in $12 \mathrm{dogs}$, such retention occurred at 8-9 wk $\left(27 \pm 2\right.$ meq $\mathrm{Na}^{+}$daily excretion), and in the remaining dogs sodium retention occurred at $7(n=2), 10(n=3)$, and at $12 \mathrm{wk}(n$ $=1$ ), with daily excretion averaging $25.6 \pm 4 \mathrm{meq} / \mathrm{d}$. Ascites occurred 4-12 d after onset of sodium retention. The time of onset of sodium retention, as early as 5 wks postbiliary obstruction (dogs cirrhotic by liver biopsy), is in keeping with previous observations made in this canine model by Better and Massry (13). Similar observations with regard to the temporal relationship of urinary sodium retention and the appearance of ascites were made in five dogs with biliary cirrhosis with an end-to-side PCA. ${ }^{3}$ In these dogs, sodium retention occurred on the averge at 7 wk (range: 6-9 wk), with ascites appearing $8 \mathrm{~d}$ later. Thus, in 23 of 24 dogs ingesting $35 \mathrm{meq} / \mathrm{d}$ of sodium, significant urinary sodium retention was present by $10 \mathrm{wk}$ in this model of biliary cirrhosis. In this study, none of 11 dogs, ingesting the same diet, displayed persistent urinary sodium retention when examined at 10-12 wk, despite equivalent degrees of cirrhotic damage as judged by liver biopsy and liver function tests.

Of these 11 dogs, who were ascites-free and in sodium balance on a $35 \mathrm{meq} / \mathrm{d}$ sodium diet, nine were placed in large metabolic cages and given a daily sodium diet of 85 meq. Two dogs were not placed in such cages for further study because it was judged they might not survive, owing to the severity of their liver disease.

The dogs in the metabolic cages were on this increased sodium intake for a total of 6-7 d. At the end of this period, eight of nine dogs remained in sodium balance and did not develop ascites. One dog displayed sodium retention and developed detectable ascites after $5 \mathrm{~d}$. For the eight dogs remaining in balance, the weight changed from $13.10 \pm 1.0$ to $13.48 \pm 1.21 \mathrm{~kg}(P>0.05)$. 
During the last $3 \mathrm{~d}$ of the increased sodium intake, urinary sodium concentration averaged 179.2 \pm 57.6 meq/liter compared with $77 \pm 12 \mathrm{meq} / \mathrm{liter}$ when the dogs were ingesting 35 meq $\mathrm{Na}^{+} / \mathrm{d}(P<0.05)$. Daily sodium excretion increased from $37.6 \pm 5.9 \mathrm{meq} / \mathrm{d}$ while on the lower sodium intake to $81.7 \pm 8.1 \mathrm{meq} / \mathrm{d}$ during the last $3 \mathrm{~d}$ of the increased sodium intake, a value not significantly different from the amount of ingested sodium. By contrast, the one dog who had developed ascites was excreting $40 \mathrm{meq} / \mathrm{d}$ of sodium while on the increased intake of salt.

In response to DOCA, administered while maintaining sodium intake at $85 \mathrm{meq} / \mathrm{d}$, the nine dogs separated out into two groups. Five dogs (including the one animal who already had ascites) developed severe sodium retention, weight gain, and developed significant ascites. Most of these dogs were subjected to final experimentation within 1-2 d after cessation of the DOCA and sodium balances were generally not continued. In one dog who was monitored for 4-5 days post-DOCA, there was a rebound diuresis and the ascites in that dog completely disappeared by external examination.

Four dogs showed transient sodium retention while receiving DOCA, but then displayed the classical DOCA-escape phenomenon and returned to sodium balance (14). None of these animals developed detectable ascites. All four dogs had a rebound diuresis when the DOCA was stopped.

Table III summarizes some data for the four escape dogs and the five nonescape dogs. These two groups did not differ from each other or from the massed group data given in Table I with regard to plasma composition. The values shown in Table III, representing the situation before the administration of the high salt diet

TABLE III

Some Features of Cirrhotic Dogs Given Intramuscular DOCA

\begin{tabular}{lcc}
\hline & $\begin{array}{c}\text { DOCA escape } \\
(n=4)\end{array}$ & $\begin{array}{c}\text { Nonescape } \\
(n=5)\end{array}$ \\
\hline Liver histology & $\begin{array}{c}\text { 1 early cirrhosis } \\
3 \text { advanced cirrhosis }\end{array}$ & $\begin{array}{c}\text { 2 early cirrhosis } \\
3 \text { advanced cirrhosis }\end{array}$ \\
Plasma volume & & \\
$(\mathrm{ml})$ & $693 \pm 24$ & $775 \pm 62$ \\
$C_{\mathrm{IN}}(\mathrm{ml} / \mathrm{min})$ & $57.2 \pm 3.6$ & $58 \pm 4$ \\
Plasma protein, & & \\
$(\mathrm{g} / \mathrm{dl})$ & $4.4 \pm 0.3$ & $4.3 \pm 0.5$ \\
Serum bilirubin, & & \\
$(\mathrm{mg} / 100 \mathrm{ml})$ & $3.43 \pm 0.70$ & $3.93 \pm 0.66$ \\
SGOT $(I U)$ & $67.3 \pm 14$ & $60 \pm 12$ \\
\hline
\end{tabular}

All values (except the liver biopsies) in this table were obtained just before administering the high salt diet and DOCA. Variables are not significantly different from each other for each group.

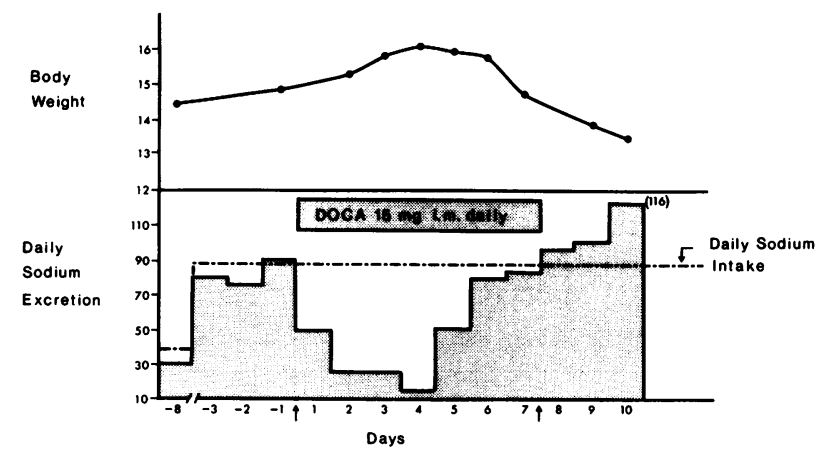

Figure 1 Response in a single representative dog (body weight in kilograms and daily sodium excretion in milliequivalents) who did not form ascites in response to daily DOCA administration. Note that dog is in sodium balance while ingesting $85 \mathrm{meq} / \mathrm{d}$. The animal showed a classical DOCA-escape phenomenon. Note rebound diuresis and loss of weight when DOCA stopped despite persistent high salt intake.

and DOCA, do not differ between the two groups in their eventual response to the mineralocorticoid. Thus, none of these variables permitted a prediction as to how the dogs would respond to DOCA.

Figs. 1 and 2 show the response to the high salt intake and DOCA for a single representative animal from each group. Several days after cessation of the DOCA, the animals were killed for final study and examination of the ss-PCA. All four dogs who had escaped from DOCA had widely patent anastomoses without a significant pressure gradient across the PCA. The periportal lymphatics and thoracic duct were collapsed and there was no evidence for ascites. Table IV summarizes these findings, as well as the pressure measurements for those dogs who failed to escape from DOCA.

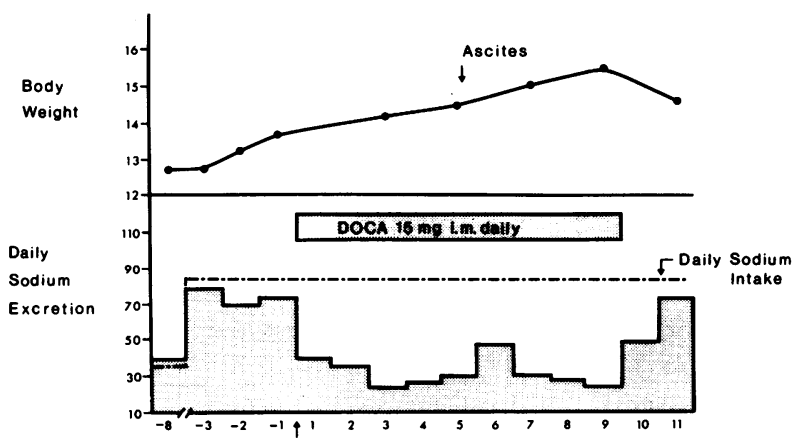

FIGURE 2 Response in a single representative dog (body weight in kilograms and daily sodium excretion in milliequivalents) who formed ascites and did not escape from DOCA. Note animal's weight continuously increases while on DOCA. When DOCA was stopped, animal returns to sodium balance. 
TABLE IV

Some Hemodynamic Features in Dogs Who either Escaped from DOCA or Formed Ascites

\begin{tabular}{|c|c|c|}
\hline & $\begin{array}{l}\text { DOCA escape } \\
\quad(n=4)\end{array}$ & $\begin{array}{l}\text { Ascites formation } \\
\qquad(n=5)\end{array}$ \\
\hline Thoracic duct & Collapsed & $4^{+}$distention \\
\hline Periportal lymphatics & Collapsed & $4^{+}$distention \\
\hline Portacaval anastomosis & Patent & Partially occluded ${ }^{\bullet}$ \\
\hline Caval pressure $\left(\mathrm{cm} \mathrm{H}_{2} \mathrm{O}\right)$ & $6.4 \pm 0.26$ & $6.5 \pm 0.28$ \\
\hline Portal pressure $\left(\mathrm{cm} \mathrm{H}_{2} \mathrm{O}\right)$ & $8.0 \pm 0.09$ & $13.5 \pm 0.12 \S$ \\
\hline $\begin{array}{l}\text { Portacaval gradient } \\
\qquad\left(\mathrm{cm} \mathrm{H}_{2} \mathrm{O}\right)\end{array}$ & 1.6 & $7.0 \$$ \\
\hline $\begin{array}{l}\text { Portal pressure (post- } \\
\text { clamping) } \ddagger\left(\mathrm{cm} \mathrm{H}_{2} \mathrm{O}\right)\end{array}$ & $22 \pm 0.09$ & $22 \pm 1.4$ \\
\hline
\end{tabular}

- One shunt appeared to be widely patent, but the gradient between portal vein and abdominal cava was $9.5 \mathrm{~cm} \mathrm{H}_{2} \mathrm{O}$.

$\downarrow$ Portal venous pressure in normal dogs is usually between 10 and $12 \mathrm{~cm} \mathrm{H}_{2} \mathrm{O}$ in our laboratory.

$\S P<0.05$.

All who failed to escape from DOCA showed partially occluded anastomoses, save one dog where the $\mathrm{PCA}$ appeared to be patent, but the gradient across the PCA was $9.5 \mathrm{~cm} \mathrm{H}_{2} \mathrm{O}$. All of the dogs who failed to escape from DOCA had ascites, except one where it had disappeared before it was killed. The dog who had developed ascites while only on the high salt diet had a ss-PCA that was only slightly patent, with a portacaval gradient of $14.5 \mathrm{~cm} \mathrm{H}_{2} \mathrm{O}$. Of interest was the observation that, no matter whether the PCA was widely patent or partially occluded, clamping the shunt caused equivalent elevations of portal venous pressure in each group, suggesting equivalent degrees of cirrhosis, venous outflow block, and potential portal hypertension for all dogs and that, furthermore, the ss-PCA had normalized intrahepatic pressures in the four dogs displaying DOCA-escape.

The two dogs who were not placed in balance cages and treated with increased dietary salt and who were free of sodium retention and ascites also had wide-open patent anastomoses at time of death. Therefore, of 11 dogs who remained free of ascites and urinary sodium retention on an ordinary laboratory diet of sodium, seven had patent PCA and four had partially occluded anastomoses.

It was not technically feasible to measure HVWP in the laboratory. In two cirrhotic dogs, we were able to obtain fluoroscopic studies in the Department of Radiology, Royal Victoria Hospital, and demonstrated retrograde flow (portal vein to cava in a caudal direction in each case). In one dog, we did measure HVWP.
This animal had failed to escape from DOCA and had developed ascites. The portacaval anastomosis was partially occluded and portal venous pressure measured $14.0 \mathrm{~cm} \mathrm{H}_{2} \mathrm{O}$. The $\mathrm{HVWP}$ was recorded at $15.0 \mathrm{~cm}$ $\mathrm{H}_{2} \mathrm{O}$. This is comparable to a recent study in $18 \mathrm{dogs}$ with chronic biliary cirrhosis at $8 \mathrm{wk}$, where portal pressure was measured at $13.3 \pm 0.6 \mathrm{mmHg}$ and HVWP at $14.1 \pm 1.2 \mathrm{mmHg}(15)$. In one normal animal, we measured a $\mathrm{HVWP}$ of $7.0 \mathrm{~cm} \mathrm{H}_{2} \mathrm{O}$, which is similar to measurements made in other labortories (15).

\section{DISCUSSION}

There is evidence that, in man with alcoholic cirrhosis $(16,17)$ and in the $\operatorname{dog}(4)$ and rat $(2,3)$ with experimental portal cirrhosis, urinary sodium retention will occur early during the course of the disease, well before ascites collects within the peritoneal compartment. In the canine model of cirrhosis, which has been thoroughly studied in our laboratory (4-8), this early, or first-phase, sodium retention is associated with plasma volume expansion, which precedes ascites formation, and is thought to be mediated, at least in part, by factors other than disturbed central hemodynamics or a compromised EABV.

As the severity of the liver disease progresses, the cirrhotic dog develops increasing amounts of ascites; shows progressive gastrointestinal hemorrhage; develops elevated plasma levels of renin, aldosterone, and estrogens; and displays signs of vascular underfilling $(4,5)$. Superficial veins collapse and plasma volume contracts as dogs decrease their dietary intake. ${ }^{5}$ The late, or second-phase, sodium retention now observed presumably represents the sodium retention of a contracted EABV and will subsume the factors responsible for early sodium retention.

To examine further the nature of the factors responsible for first-phase sodium retention, we conducted studies in a canine model of cirrhosis with a coexistent ss-PCA. Numerous studies have established the effectiveness of such a PCA in returning previously elevated sinusoidal pressures to normal $(10,18-20)$. Although it is known that either a combination of a cirrhotic liver and intrahepatic hypertension (7) or intrahepatic hypertension alone $(21,22)$ are potent sodium retaining states, it is not known whether a cirrhotic liver per se will also provide a sodium retaining stimulus. This study attempted to answer this question.

Our results clearly demonstrate that the 13 animals studied showed a profile of responses, depending on the state of the PCA. When the anastomosis closed

${ }^{5}$ Levy, M, and M. J. Wexler. Unpublished observations. 
(two dogs), hepatoportal hypertension developed and marked sodium retention and ascites soon developed. Where the PCA remained partially or completely patent, 11 dogs, while ingesting $35 \mathrm{meq} / \mathrm{d} \mathrm{Na}^{+}$, remained free of sodium retention and ascites. When nine of these 11 dogs were challenged with a high salt diet $\left(85 \mathrm{meq} \mathrm{Na}^{+} / \mathrm{d}\right.$ ), eight of the nine remained in sodium balance and only one developed ascites. When DOCA was added intramuscularly, four dogs with a completely patent PCA and no portacaval pressure gradient escaped, whereas those with a partially occluded PCA or a portacaval pressure gradient did not escape from DOCA and developed sodium retention and ascites. ${ }^{6}$ These results are in keeping with the hypothesis that the component of urinary sodium retention observed in cirrhotic dogs (when precautions have been taken to exclude ascites sequestration, mesenteric venous congestion, hyperaldosteronism, and a compromised EABV $[7,8]$ as determinants of sodium retention) is due to intrahepatic hypertension.

Three conditions must prevail before these observations are acceptable. First, the dog with chronic biliary cirrhosis must be similar, especially in regard to renal physiology, to the dog with portal cirrhosis that served as the model for previous investigations in this laboratory (4-8). This appears to be so. These dogs develop histological features of cirrhosis replete with regenerative nodules, portal venous hypertension, disturbed liver function tests, ascites, and portasystemic venous collaterals. They also develop the muscle wasting typical of cirrhosis. As noted in this and another recent study from this laboratory, ${ }^{3}$ renal perfusion remains normal in these animals until the terminal phase of the disease. The temporal relationships between sodium retention, plasma volume expansion, and ascites formation are similar to those observed in dogs with portal cirrhosis (4), and have been reported in the Results section. Other investigators have documented portasystemic shunting of blood in these animals (15) and have observed venous outflow obstructive patterns identical to those observed for portal cirrhosis (23). In fact, dogs with biliary cirrhosis appear to differ from dogs with portal cirrhosis only in the extent of the

\footnotetext{
${ }^{6}$ Of the five dogs who did not escape from DOCA, four had partially occluded ss-PCA, and in one it appeared to be patent. In this dog, however, the PCA was apparently unable to provide for the hepatic blood flow, since a portacaval gradient of $9.5 \mathrm{~cm} \mathrm{H}_{2} \mathrm{O}$ was present, as well as ascites. Since fluid can leave the vascular space only when Starling forces are disturbed, there was presumably sufficient portal venous hypertension to permit ascites formation when DOCA was administered.
}

jaundice they develop. We have also demonstrated that dogs with biliary cirrhosis in whom ascites has been mobilized with a LeVeen valve will continue to display sodium retention (unpublished observations). There seems little doubt therefore that dogs with chronic biliary cirrhosis are equivalent physiologically to dogs with portal cirrhosis by feeding dimethylnitrosamine (4), a model we have stopped using because of the putative carcinogenic properties of this compound.

Second, at the time of observation, the dogs must truly have cirrhosis of the liver. This condition was fulfilled in that each biopsy from all 13 dogs was compatible with histological cirrhosis. When the PCA spontaneously closed in two animals, the existence of cirrhosis expressed itself with the advent of portal venous hypertension and ascites. Although several dogs showed incomplete fibrous bridging and no regenerative nodules, it must be emphasized that dogs with biliary cirrhosis, portal hypertension, and ascites, but without a PCA, may have the same type of biopsy. Moreover, dogs with portal cirrhosis routinely have no regenerative nodules, although they may have the complete clinical picture of cirrhosis (4).

These biopsies are taken at an earlier stage in the disease than human counterparts. As Foulk and Baggenstoss (12) have emphasized, the changes cited in the four dogs without complete fibrous bridging should be regarded as early cirrhosis. In any event, our experimental findings correlated not with the degree of histological injury, but rather with the status of the PCA.

Third, the creation of a ss-PCA should realistically have reduced intrahepatic sinusoidal pressure. Unfortunately, fluoroscopic facilities for the proper measurement of HVWP were not routinely available to us. There are, however, several lines of evidence that strongly suggest that intrahepatic pressures in the dogs with a fully patent PCA were normalized. First, neither in the two dogs without ascites and sodium retention with a patent PCA studied before DOCA administration nor in the four dogs with a patent PCA who escaped from intramuscular DOCA, did we ever observe dilated periportal lymphatics or an engorged thoracic duct. Such an observation is routinely made in chronic caval dogs with ascites or in cirrhotic dogs with ascites. Indeed, in dogs with portal cirrhosis examined in a sodium-retaining but preascitic phase, thoracic duct lymph flow was already increased by $300 \%$ (7). The formation of hepatic lymph and the engorgement of regional lymphatics is exquisitely dependent upon changes in hepatic sinusoidal pressure. Laine et al. (24) have recently demonstrated that sequential graded increments in hepatic venous pressure produce stepwise parallel increments in sinusoidal pressure and hepatic 
lymph flow. Within $3 \mathrm{~min}$ of an increment in hepatic venous pressure, lymph flow from the liver increases and stablizes at new steady-state levels. So sensitive in this dependency that hepatic lymph flow in the dog was found to increase $63 \%$ for every $1 \mathrm{mmHg}$ elevation of sinusoidal pressure. Thus, the absence of engorged hepatic lymphatics or a thoracic lymph duct is powerful evidence that intrahepatic vascular pressures were not significantly elevated.

Second, without clamping of the PCA, portal pressure averaged $8.0 \pm 0.09 \mathrm{~cm} \mathrm{H}_{2} \mathrm{O}$ in the dogs who escaped from DOCA. When the PCA was clamped, portal venous pressure quickly rose to the cirrhotic range $(22 \pm 0.09)$, indicating that the PCA had previously normalized pressures in the venous system. Because blood does not flow up pressure gradients, the likelihood is that normalized intrahepatic pressures prevailed in the presence of normal portal venous pressures.

Third, in two cirrhotic dogs where we did obtain fluoroscopic studies, retrograde flow was demonstrated upon injection of radiocontrast high in the portal vein. ${ }^{7}$ Even though the PCA was partially occluded, the HVWP was identical to portal venous pressure. If HVMP was equivalent to portal pressure when the ssPCA was partially open, there is no reason to think that such equivalence would not pertain when the ssPCA is completely patent and portal pressure is normal.

Last, in many clinical studies $(10,18-20)$, it has been frequently demonstrated that an ss-PCA normalizes HVWP when direct measurements are made. Moreover, studies have demonstrated the very close correlation between measurements of portal venous pressure and HVWP $(25,26)$. In dogs with hepatic venous outflow block produced by mechanical ligation, the creation of an ss-PCA is known to cause reversal of portal flow and the normalization of intrahepatic pressures $(9,27)$.

As if to lend further support to our observation that first-phase sodium retention is dependent upon intrahepatic hypertension, four dogs with a partially occluded PCA and one with an apparently open PCA but with a significant portasystemic pressure gradient developed sodium retention and ascites when given a high salt diet and DOCA. When DOCA was stopped, in one dog where sufficient observations were made,

\footnotetext{
${ }^{7}$ A catheter was inserted into a femoral vein and passed up the abdominal vena cava. The PCA was transversed and contrast material injected on the hepatic side of the anastomosis. The dye then was observed to flow retrograde down the portal vein, cross the PCA, and disappear proximally up the vena cava.
}

the ascites completely disappeared. In no case did any dog with a partially occluded PCA and elevated portal venous pressure escape from DOCA or not form ascites. These observations are consistent with those reported by Massry and Klein (28), where dogs with chronic biliary cirrhosis were subjected to DOCA at various stages in the development of the liver disease. Early on, sodium retention was followed by escape. As the chronic process, and presumably the portal venous hypertension progressed, the duration and intensity of DOCA-induced sodium retention became greater, while the DOCA escape became less in magnitude. 5-9 wk after bile duct obstruction, DOCA escape no longer occurred, and administration of this mineral-corticoid produced permanent sodium retention. At this point in time, ascites soon followed. These observations, although open to various interpretations, seem to imply that DOCA escape occurs only early in the course of chronic liver disease, where intrahepatic hypertension has not yet appeared. Once developed, a progressive sodium retaining influence becomes apparent, which finds expression as ascites only in the presence of significant disturbances in Starling forces along the hepatoportal vascular system.

Several other lines of evidence confirm that intrahepatic sinusoidal hypertension is a potent sodium-retaining stimulus to the renal tubule. Hanback (29), Levy (21), Orloff et al. (27), and Campbell et al. (22) have reported the results of canine experiments when specific obstruction to hepatic venous outflow (but not presinusoidal venous block) caused a marked reduction in urinary sodium excretion. Davis and Ball (30) and Levy et al. (8) have shown that in chronic caval dogs without ascites one may still detect urinary sodium retention.

Although we had not documented urinary sodium retention in the cirrhotic dogs while ingesting a normal chow diet ( $35 \mathrm{meq} \mathrm{Na}^{+} / \mathrm{d}$ ), one could argue that such a phenomenon was missed because we had not performed daily sodium balances. Three sequences are possible $(a)$ They were free of sodium retention during the entire 10-wk period of observation while on the $35 \mathrm{meq} \mathrm{Na}{ }^{+} / \mathrm{d}$ diet. If this were the case, our thesis that normalizing intrahepatic pressure in cirrhotic dog abolishes the sodium retaining tendency is correct. One cannot use the argument that this level of sodium intake is too low, since cirrhotic dogs who are allowed to develop portal hypertension while on this diet will develop sodium retention and ascites. (b) Urinary sodium retention transiently occurred, but the dogs returned to sodium balance. If this had occurred, we would have expected to find expanded plasma volumes, since the absence of altered Starling forces would have permitted such expansion to occur. Since 
we did not, this option therefore seems unlikely. (c) It is unlikely that continuous sodium retention was occurring, since we would have anticipated limb edema in the absence of portal venous hypertension. This was not observed. It should be emphasized that when cirrhotic dogs truly had urinary sodium retention without the capability of forming ascites (LeVeen valve) sodium challenges resulted in marked limb edema (8). Four of five dogs with mild portal hypertension were able to remain in sodium balance even when consuming a high salt diet in this study. While escape from DOCA is a measure of normalized intrahepatic pressure, it is difficult to escape the conclusion that sodium balance on $35 \mathrm{meq} \mathrm{Na}^{+} / \mathrm{d}$ really represents a true absence of a sodium retaining state.

In the present study, plasma volume did not increase as the animals became progressively cirrhotic. Although it is true that plasma volume/body weight increased, this should be looked upon as an expression of muscle wasting rather than as true volume expansion. There is after all, no a priori reason why the tissue capillary network should decrease in capacity as muscles waste. Moreover, Moore and associates (31) have demonstrated in elegant and thorough studies that it is a common feature of all wasting diseases that plasma volume/ body weight rises as the latter variable falls. This phenomenon also occurs in normal subjects. Thus, these investigators collated material from various sources (six separate studies) for adult men and found that the relationship between plasma volume and body weight may be expressed as "volume" $=927+31.47$ (body weight) $(r=0.81 ; P<0.01)$. According to this formula, plasma volume/body weight would increase from 43 to $50 \mathrm{ml} / \mathrm{kg}$ as weight declined from 80 to $50 \mathrm{~kg}$. Moore et al. (31) further provides evidence that wasting is accompanied by an intact extracellar aqueous phase while cell mass and intracellular fluids shrink. Plasma volume is thus maintained as body weight falls. A similar situation is found in patients with cirrhosis of the liver (31).

It should also be pointed out that in this study, plasma volume/body weight rose from $38.1 \pm 1.3$ to $53.0 \pm 1.9 \mathrm{ml} / \mathrm{kg}$, simply because of weight loss. In another series of cirrhotic dogs where significant muscle wasting had occurred (4), plasma volume/body weight was of the order of $60-63 \mathrm{ml} / \mathrm{kg}$, when one corrects for the presence of ascites and where true plasma volume expansion is present. Thus, the increase in plasma volume/body weight is an apparent one and does not imply that sodium retention had previously occurred. In any event, the fact that the difference in plasma volumes (Table II) was only $42 \mathrm{ml}$ implies (in the absence of ascites) a total increase in extracellular fluid of $168 \mathrm{ml}$ (plasma volume is $25 \%$ of total extracellular fluid). Given that the plasma sodium in all phases of the experiment was $149 \mathrm{meq} / \mathrm{liter}$, only $25.0 \mathrm{meq}$ of sodium would have been retained over the entire 10wk period, or an average of $0.36 \mathrm{meq} / \mathrm{d}$. Such minute requirements for net sodium addition does not suggest an operative sodium retaining stimulus. The alternative-viz., that the sodium was retained over a short period of time with return of the animals to salt balance-is possible, but seems unlikely given that cirrhotic dogs in whom vascular fullness has been restored with a LeVeen valve (reference 8 and unpublished observations) will demonstrate continuous sodium retention. Moreover, when the sodium intake was increased, no salt-retaining tendency could be demonstrated.

If our observations are correct, it suggests that firstphase sodium retention in the cirrhotic dog is dependent upon a baroreceptor or stretch receptor within the hepatic parenchyma. Several groups of investigators (32, 33), have indeed documented such a baroreceptor function for the canine liver. Recently, Kostreva et al. (32) have shown that causing intrahepatic hypertension by constricting the supradiaphragmatic vena cava will excite hepatic baroreceptors and simultaneously cause reflex excitation in the renal and cardiopulmonary sympathetic efferents. Thus, the anatomic structures for a possible liver-heart-kidney and liver-kidney loop for the control of sodium balance appear to be in place. Recently, Moreno and Burchell (34) have suggested that the liver may play a central role in regulating plasma volume through baroreceptor signaling of the renal tubule.

Although we believe that putative hepatic low-pressure baroreceptors may signal the renal tubule directly, it is possible that a liver-kidney loop is mediated by changes in peripheral vascular resistance. We did not measure vascular resistance and cardiac output longitudinally in these studies and so are unable to say if the anticipated changes (a fall in vascular resistance and an increment in cardiac output) actually occurred. Although it is possible that by alleviating intrasinusoidal hypertension we prevented a reflex-induced change in peripheral vascular resistance, it is more likely that the opening of arteriovenous shunts in advanced cirrhosis is due to humoral factors. In any event, in dogs with portal cirrhosis, we have already shown that urinary sodium retention is antecedent to a detectable change in peripheral vascular resistance (6).

In summary, we demonstrated that dogs with chronic biliary cirrhosis of the liver but without intrasinusoidal hypertension will not display urinary sodium retention or form ascites unless the ss-PCA used to vent liver flow becomes occluded. When placed on a high salt 
diet and given intramuscular DOCA, dogs will escape if the PCA is completely patent, but will retain sodium and form ascites if the PCA is partially occluded and a portacaval pressure gradient develops. These results are consistent with a baroreceptor within the hepatic parenchyma which may send a sodium retaining signal to the renal tubule when intrahepatic hypertension is present, even though systemic hemodynamics and circulating plasma volume are normal.

\section{ACKNOWLEDGMENTS}

We are indebted to Mrs. Christine Fechner and Mrs. Olga Lawryk for expert technical assistance. Dr. Serge Jothy of the Pathology Department, Royal Victoria Hospital, interpreted the liver and kidney biopsies. Dr. Larry Stein of the Radiology Department arranged for fluoroscopy facilities to be made available for animal use. Mrs. C. Pamplin provided expert secretarial assistance.

This investigation was aided by an operating grant from the Kidney Foundation of Canada.

\section{REFERENCES}

1. Lopez-Novoa, J. M., M. A. Rengel, J. L. Rodicio, and L. Hernando. 1977. A micropuncture study of salt and water retention in chronic experimental cirrhosis. Am. J. Physiol. 232:F315-F318.

2. Lopez-Novoa, J. M., M. A. Rengel, and L. Hernando. 1980. Dynamics of ascites formation in rats with experimental cirrhosis. Am. J. Physiol. 238:F353-F357.

3. Linas, S. L., R. J. Anderson, S. J. Guggenheim, G. L. Robertson, and T. Berl. 1981. Role of vasopressin in impaired water excretion in conscious rats with experimental cirrhosis. Kidney Int. 20:173-180.

4. Levy, M. Sodium retention and ascites formation in dogs with portal cirrhosis. 1977. Am. J. Physiol. 233:F572F585.

5. Levy, M. 1977. Sodium retention in dogs with cirrhosis and ascites: efferent mechanisms. Am. J. Physiol. 233:F586-F592.

6. Levy, M., and J. B. K. Allotey. 1978. Temporal relationships between urinary salt retention and altered systemic hemodynamics in dogs with experimental cirrhosis. J. Lab. Clin. Med. 92:560-569.

7. Levy, M., and M. J. Wexler. 1978. Renal sodium retention and ascites formation in dogs with experimental portal cirrhosis but without portal hypertension or increased splanchnic vascular capacity. J. Lab. Clin. Med. 91:520-536.

8. Levy, M., M. J. Wexler, and C. McCaffrey. 1979. Sodium retention in dogs with experimental cirrhosis following removal of ascites by continuous peritoneovenous shunting. J. Lab. Clin. Med. 94:933-946.

9. Bono, R. F., A. H. Moreno, L. M. Rousselot, and J. Burke. 1962. On the ability of the portal vein to act as a hepatic outflow tract in the normal dog. Surg. Forum. 13:320324.

10. Mulder, D. G., W. G. Plested III, W. N. Hanafee, and J. F. Murray. 1966. Hepatic circulatory and functional alterations following side-to-side portacaval shunt. Surgery (St. Louis). 59:923-931.

11. Bernstein, L., and M. Weatherall. 1952. Statistics for Medical and Other Biological Students. E. and S. Livingstone Ltd., Edinburgh. 1:74-79.

12. Foulk, W. T., and A. H. Baggenstoss. 1975. Biliary cirrhosis. In Diseases of the Liver. Leon Schiff, editor; J. B. Lippincott Co., Philadelphia. Fourth ed. 4:940-970.

13. Better, O. S., and S. G. Massry. 1972. Effect of chronic bile duct obstruction on renal handling of salt and water. J. Clin. Invest. 51:402-411.

14. August, J. T., D. H. Nelson, and G. W. Thorne. 1958. Response of normal subjects to large amounts of aldosterone. J. Clin. Invest. 37:1549-1553.

15. Bosch, J., E. H. Storer, R. Enriquez, and R. J. Groszman. 1982. Chronic bile duct ligation in the dog: hemodynamic characterization of a portal hypertensive model. Gastroenterology. 82:1223. (Abstr.)

16. Naccarato, R., P. Messa, A. D'Angelo, A. Fabris, M. Messa, M. Chiaramonte, C. Gregolin, and G. Zanon. 1981. Renal handling of sodium and water in early chronic liver disease. Gastroenterology. 81:205-210.

17. Papper, S., and J. D. Rosenbaum. 1952. Abnormalities in the excretion of water and sodium in "compensated" cirrhosis of the liver. J. Lab. Clin. Med. 50:523-530.

18. Mulder, D. G., and J. F. Murray. 1960. An evaluation of the side-to-side portacaval shunt. Surg. Forum. 11:278-279.

19. Burchell, B. R., A. H. Moreno, W. F. Panke, and T. F. Nealon, Jr. 1974. Hemodynamic variables and prognosis following portacaval shunts. Surg. Gynecol. Obstet. 138:359-369.

20. Redeker, A. G., C. T. Kunelis, S. Yamamoto, and T. B. Reynolds. 1964. Assessment of portal and hepatic hemodynamics after side-to-side portacaval shunt in patients with cirrhosis. J. Clin. Invest. 43:1464-1471.

21. Levy, M. 1974. Renal function in dogs with acute selective hepatic venous outflow block. Am. J. Physiol. 227:1074-1083.

22. Campbell, V., P. D. Greig, J. Cranford, B. Langer, M. Silverman, and $L$. M. Blendis. 1982. A comparison of acute reversible pre- and post-sinusoidal portal hypertension on salt and water retention in the dog. Hepatology (Baltimore). 2:54-58.

23. Gliedman, M. L., R. E. Giradet, A. Schwartz, R. Ryzoff, B. Lerner, and K. E. Karlson. 1964. Hepatic vascular anatomy and manometry in experimental biliary obstruction and ascites. Surg. Gynecol. Obstet. 119:749757.

24. Laine, G. A., J. T. Hall, S. H. Laine, and H. J. Granger. 1979. Transsinusoidal fluid dynamics in canine liver during venous hypertension. Circ. Res. 45:317-323.

25. Viallet, A., J. G. Joly, D. Marleau, and P. Lavoie. 1970. Comparison of free portal venous pressure and wedged hepatic venous pressure in patients with cirrhosis of the liver. Gastroenterology. 59:372-375.

26. Loisance, D. Y., P. A. Peronneau, M. P. Pellet, and J. P. Lenriot. 1973. Hepatic circulation after side-to-side portacaval shunt in dogs: velocity pattern and flow rate changes studied by an ultrasonic velocimeter. Surgery (St. Louis). 73:43-52.

27. Orloff, M., J. Spitz, B. R. Wail, M. H. Thomas, and N. A. Halasz. 1964. Experimental ascites. IV. Comparison of the effects of end-to-side and side-to-side por- 
tacaval shunts on intractable ascites. Surgery (St. Louis). 56:784-796.

28. Massry, S. G., and K. L. Klein. 1978. Effects of bile duct ligation on renal function. In The Kidney in Liver Disease, Murray Epstein, editor. Elsevier, North Holland, New York. First ed. 155-166.

29. Hanback, L. J., Jr. 1970. Renal hemodynamics following minimal hepatic venous outflow block. Surg. Forum. 21:364-366.

30. Davis, J. O., and W. C. Ball, Jr. 1958. Effects of a body cast on aldosterone and sodium excretion in dogs with experimental ascites. Am. J. Physiol. 192:538-542.

31. Moore, F. D., K. H. Olesen, J. D. McMurray, H. V. Parker, M. R. Ball, and C. M. Boyden. 1963. The Body Cell Mass and its Supporting Environment: Body Com- position in Health and Disease. W. B. Saunders Co., Philadelphia. 67, 173-223, 491, and 505.

32. Kostreva, D. R., A. Castaner, and J. P. Kampine. 1980. Reflex effects of hepatic baroreceptors on renal and cardiac sympathetic nerve activity. Am. J. Physiol. 238:R390-R394.

33. Tyryshkina, E. M. 1980. Electrophysiological pattern and functional role of the liver mechanoreceptors. Sechenov Physiol. J. USSR (Engl. Transl. Fiziol. Zh. SSSR Im. I. M. Sechenova). 16:984-990.

34. Moreno, A. H., and A. R. Burchell. 1982. Respiratory regulation of splanchnic and systemic venous return in normal subjects and in patients with hepatic cirrhosis. Surg. Gynecol. Obstet. 154:257-267. 